\title{
Vicente Riva Palacio, cuentista
}

V

ICENTE Riva Palacio, el genial diplomático, militar y hombre de letras, tal vez nunca pensó que no poca de su fama literaria se debería a un pequeño volumen de cuentos que acababa de ver la luz pública en Madrid cuando le sorprendió la muerte. Algunos de los Cuentos del General (1896), ya clásicos en la literatura mexicana, habían sido publicados en España -en una de las revistas más importantes de la épocacon el objeto de demostrar a los literatos españoles que el representante de México en la Corte sabía manejar la prosa castellana como el mejor. La feliz idea de publicar estos donosos cuentos - y no otra indigesta novela histórica de la época colonial - le valiô al General el que su nombre perdure en los anales de la literatura mexicana como el de uno de los mejores cuentistas del siglo xIx. Antes de Riva Palacio solamente Roa Bárcena había publicado, en México, cuentos dignos del nombre. Estos dos escritores pueden ser considerados como los verdaderos creadores del cuento mexicano moderno.

Según parece, cuando Riva Palacio pasó a España en 1886 como Embajador de México, ya llevaba en la maleta-como las había llevado tres siglos antes su compatriota don Juan Ruiz de Alarcón y Mendoza- algunas de las obras que le habían de dar fama en la Corte. ¿Cuándo empezó Riva Palacio - cabe preguntar-a escribir cuentos? Lo excelente de su colección nos hace pensar que ya había ensayado el género. Como hemos sugerido, parece que varios de los Cuentos del General fueron escritos antes de 1886, año en que el autor llegó a Madrid. Uno de ellos, "El buen ejemplo", ya había apa- 
recido - como hizo notar Manuel Toussaint ${ }^{1}$ - en Los Ceros, obra de Riva Palacio que vio la luz pública en México en 1882. Allí, sin embargo, el cuento es apenas un bosquejo de lo que había de ser en su forma definitiva. La popularidad de la anécdota queda bien demostrada por su frecuente reproducción en los periódicos de la época. Tenemos noticias de que apareció en El Siglo XIX el primero de noviembre de 1892 y el 12 de febrero de 1896; y sin duda apareció en otros periódicos. La predilección que el General sentía por los "cuentos de pericos", tan populares en México, lo demuestra el haber incorporado en su artículo-retrato de don Justo Sierra - también en Los Ceros - la chispeante anécdota, "Perdone usted, caballero..."

Mas no es el anterior el primer cuento de Riva Palacio. No hay duda que ya para 1882 había publicado algunos otros. En 1867, por ejemplo, aparece en las páginas de La Orquesta, redactada en aquel entonces por Riva Palacio, un "Cuento" que, aunque sin nombre de autor, estamos seguros es obra del General. 'Como es bien sabido, en el siglo XIX en México los redactores de periódicos eran responsables de todos los artículos sin firma; además, aquello de decir que el alcalde - cuya ignorancia se satiriza en la anécdota-se dirigió a la botica "con un aire imperioso y magistral como redactor de periódico subvencionado por Lerdo" no deja lugar a dudas sobre la paternidad del cuento. Al año siguiente se publica en la misma revista la primera parte de otro cuento "Un viaje al Purgatorio", que quedó sin terminar y en el cual también hallamos las inconfundibles peculiaridades del estilo de Riva Palacio; aquella característica introducción: "De saber tienes, ; oh cristiano lector! que esto que te voy a referir es cuento, porque me lo contaron (como verás más adelante), pero tiene todos los visos de verdad, que era persona verídica el narrador..., y aquello de "le interpelé con toda la energía de que soy capaz, como diría D. Ezequiel Montes", son giros de estilo que se repiten con insistencia en las obras del autor. Estos bocetos de cuentos nos parecen ser los primeros ensayos en el género, ensayos

1 En la "Introducción" a su ed. de los Cuentos del General (México, 1929), pág. XV. 
que ya denotan lo que más tarde han de sex los cuentos del General; ambos relatan chispeantes anécdotas, dan principio con la característica introducción y están salpicados de agudas observaciones.

El año de 1868 es de gran actividad literaria para Riva Palacio. Además de sus tareas como redactor de La Orquesta, tiene tiempo para sus actividades políticas y para publicar nada menos que tres novelas: Calvario y Tabor, Monja y casada..., y Martín Garatuza. La primera, que trata de la guerra contra el Imperio, abre con un verdadero cuento, titulado "El delito de un veterano". El título del capítulo se debe a que en él se cuenta el delito cometido por un veterano, delito que consiste en jugar una burla a un tal Juan de Jarras. Este Juan de Jarras es el primer personaje novelístico que crea Riva Palacio. El apego de Riva Palacio hacia el nombre Juan de Jarras lo indica el haberlo usado como seudónimo cuando fue redactor de La Orquesta en 1868.

El éxito obtenido por las tres primeras novelas induce a Riva Palacio a seguir cultivando el género. Por lo tanto, en 1869 publica dos más, Los piratas del Golfo y Las dos emparedadas; al año siguiente aparece La vuelta de los muertos y en 1872. las Memorias de un impostor. Este interés en la novela le aleja, desgraciadamente, del cuento. No hay que olvidar, sin embargo, que en 1874 apareció en el folletín de La Orquesta su obra Los cuentos de un loco, no mencionada en las bibliografías y que según parece más que una colección de cuentos es otra novela. Observemos que Riva Palacio tal vez se inspiró, para el título, en la obra del mismo nombre del poeta español Zorrilla, parte de la cual - en verso-fue leída por su autor en México en 1855.

Los años que van de 1874 a 1878 son de gran actividad política para Riva Palacio y, por lo tanto, su producción literaria disminuye. En 1874 comienza a publicar el periódico de oposición El Ahuizote, cuyas columnas contribuyeron a la caída de Lerdo. Ya adherido a la revuelta de Tuxtepec, Riva Palacio abandona la capital. Al establecerse el nuevo gobierno en 1876, Díaz le nombra Ministro de Fomento, puesto al cual dedica todas sus energías. No es hasta 1882 cuando aparece su obra Los Ceros, galería de contemporáneos, colección de in- 
teresantísimos y amenos retratos de los hombres prominentes de la época. Allí bosquejó, como ya hemos visto, el cuento "El buen ejemplo".

En 1886 Díaz nombra a Riva Palacio ministro de México en España, puesto que ocupa en seguida. No es hasta enero de 1893, sin embargo, cuando empiezan a aparecer en las páginas de la Ilustración Española y Americana" los "Cuentos del General". De los cinco que allí se publicaron, tres - "La horma de su zapato", "La leyenda de un santo", "En una casa de empeños"- - fueron recogidos en volumen; los otros dos, por razones que no nos explicamos, no aparecen entre los Cuentos del General (Madrid, 1896), ni fueron añadidos por Toussaint en su edición de 1929. Ambos cuentos, titulados "Los azotes" y "Un buen negocio", son de ambiente mexicano y pertenecen al grupo de cuentos históricos, al estilo de "Las mulas de su Excelencia", "El voto del soldado", "Las honras de Carlos V" y "Ciento por uno". El primero, "Los azotes", trata de un episodio que se remonta a la época de la conquista. El personaje central es el mismo Cortés. ${ }^{3}$ El segundo trata de la promesa que don Rosendo de Figueroa - mexicano por nacimiento, hombre capaz de hacer un buen negocio con el primero que encontrara- hace a la Virgen de Guadalupe por haberle salvado de un naufragio, y el método que utiliza para evadir el cumplimiento de dicha promesa. Tanto "Los azotes" como "Un buen negocio" son dignos de figurar entre los mejores de los Cuentos del General y no sabemos por qué no fueron recogidos por el autor, a no ser que, como participó don Luis González Obregón a Manuel Toussaint, la edición quedó incompleta debido a que la enfermedad, que le había de causar la muerte, le impidió todo trabajo: "Ei General iba vigilando la impresión; daba él mismo las instrucciones para los dibujos y sólo cuando su enfermedad le impidió todo trabajo, suspendió la impresión y el volumen fue lanzado incompleto. Por eso no aparece la palabra FIN en la página postrimera"."

2 Vol. XXXVII, núms. 2, 5, 7, 11 y 16 (enero 15; feb. 8, 22; Marzo 22, 30, 1893).

3 Tema sacado de una pintura de la época. V. Anales del Inst. de Inv. Estét., 24, 1956. Tamb. Sedano, Noticias de México, II, 159--161.

4 Op. cit., en n. 1. p. XV. 
Estos dos cuentos, según parece, pertenecen a la misma época a la cual pertenecen los ya mencionados cuentos históricos, esto es, a la época durante la cual el General estaba interesado en la historia colonial de México. "Naturalmente - dice Toussaint- no faltan los cuentos coloniales, bien porque el general los hubiese escrito en su tiempo de novelista historiador o porque, más fácil, no pudiese olvidar de pronto aquella época". " La verdad es, fuerza es decirlo, que no tenemos datos suficientes para fijar la fecha de estos cuentos. Uno de ellos, "Ciento por uno", había sido publicado en El Siglo XIX el 15 de septiembre de 1887 ; si los otros aparecieron en México antes que se publicaran en España, no tenemos noticia.

Es curioso hacer notar que precisamente la mitad de los veintiséis Cuentos del General tienęn como escenario Madrid o alguna región de España. Este hecho no es prueba evidente, por supuesto, que estos trece cuentos hayan sido escritos en España. Al mismo tiempo, ciertos rasgos de estilo, en algunos de ellos, nos hace pensar que si no fueron escritos en España cuando menos fueron retocados antes de darlos a las prensas. "Hay veces que Madrid -observa Toussaint- se le impone de tal modo, con esa fuerza irresistible de su hospitalidad y de su gracia, que pasa de lo castizo al madrileñismo (una chica de betún; eso es un camelo)".".

No es el estilo, por supuesto, prueba evidente y absoluta que determine la época a que pertenecen estos cuentos; ni tampoco lo son los temas ni el contenido. No debemos olvidar que el autor había estado en España por los años de 1870 a 1871. Además, estos cuentos que acusan la influencia madrileña podían haber sido escritos - repetimos-en México y retocados en España. Como ejemplo citemos el cuento "El divorcio", sobre el cual Toussaint dice: "Aquel cuento entero, "El divorcio", tan gracioso y fino ... todo parece inspirado, parece sentido en aquella población de incomparable hospitalidad: Madrid". El cuento, aunque haya sido escrito en Madrid, desarrolla una anécdota que Riva Palacio conocía antes de pasar a España, anécdota que había aparecido en forma de fábula en las páginas de La Orquesta en 1866. Hela aquí:

5 Ibid,, p. XVI.

6 Ibid., p. XV. 
Publicóse un día un duro bando

por su majestad leonesa,

que llamaba a toda prisa

a los brutos a su mando.

El hocico le apestaba

a su sacra majestad,

y quería ver la verdad

y si moría y si sanaba.

Llegó un perro y le dijo al punto:

Mi rey, yo claro me explico,

mucho le huele el hocico,

casi apesta a difunto.

Muere al momento, insolente,

dijo el león, porque atrevido

mi real hocico has tenido

por fétido e indecente.

Llegó el lobo, y cortesano

dijo: Sacra majestad,

nada apesta en realidad

el tu hocico soberano.

¿Nada me apesta, traidor, cuando muriéndome siento?

Para servir de escarmiento, muere por adulador.

Llegó la zorra, y taimada, dijo: monarca bizarro, yo tengo mucho catarro, y así no puedo oler nada.

Tú si que lo entiendes, Vélez, pues con Ios federalistas, centrales y monarquistas, tienes catarro y no hueles. ${ }^{7}$

Que la anécdota no es original, nos lo hace saber el mismo Riva Palacio; en la introducción del cuento dice: "Querido lector: Quizá lo que voy a referirte lo habrás escuchado o leído alguna vez; pero eso me tiene muy sin cuidado, porque recuerdo una de las máximas famosas del Barón de Andilla, que dice:

Si alguien te cuenta algo, es groseria decirle: por supuesto, lo sabia.

7 La Orquesta, México, 1a. época, II, núm. 10 (feh. 3, 1866). 
Mas si la anécdota no es original, no hay duda que el donoso modo de contarla es originalísimo. El General mejora la fábula añadiendo el personaje de la leona y creando el conflicto matrimonial. Cambia, además, al perro en pollino y al lobo en caballo y añade al mono. La pintura de estos tres animales es insuperable. La comparación del cuento de Riva Palacio y la fábula que hemos citado nos permite apreciar los méritos del General como cuentista.

Entre los Cuentos del General encontramos, además, algunos que acusan la influencia de los escritores franceses. No era Riva Palacio, por supuesto, un gran admirador de la literatura francesa. Había combatido a los franceses en México y visto con sus propios ojos las crueldades cometidas por los soldados de Napoleón III. Su novela Calvario y Tabor es una fiel pintura de los sufrimientos y penalidades por los cuales atravesó el pueblo mexicano durante estos años de intervención. Mas Riva Palacio, en cuyo espíritu reinaba en forma preponderante la idea de la conciliación, había olvidado el pasado y, al viajar por Europa en 1870 , no dejó de visitar la capital francesa. Los periódicos mexicanos hasta le acusaban de haber tomado parte en la defensa de París. Dicha acción le parecía al redactor de La Orquesta "cosa realmente increíble, si se recuerdan los antecedentes de un mexicano tan digno que tantos servicios prestó a su patria durante la intervención francesa". ${ }^{8}$ La influencia francesa, si acaso la hay en algunos de sus cuentos, como por ejemplo en "La gata coja", "La expiación", "La bestia humana" (cuyo escenario es París) y "En una casa de empeños", es una influencia casi insignificante, una influencia, dice Toussaint, "tamizada, suavizada por su espíritu de mexicano".

Además de los cuentos ya citados, nos falta hacer mención de un tipo de cuento de ambiente mexicano, pero que no es histórico ni colonial. A este tipo pertenece el titulado "La limosna", anécdota que conmovió al autor profundamente -y aquí Riva Palacio acusa un sentimentalismo que tal vez indique que el cuento pertenece a una época temprana en su desarrollo literario-y que según afirma, siente imperiosa ne-

8 Ibid., oct. 19 de 1870 . 
cesidad de contarla. Dicho cuento, lo mismo que el titulado "El hermano Cirilo", no coleccionado todavía, aparecieron en las páginas de El Siglo XIX el 4 de marzo y el 11 de junio de 1896, respectivamente. Es de interés confrontar las fechas de estos dos últimos cuentos con la de la primera edición del libro. Según afirmaba don Luis González Obregón, el libro no fue póstumo. "Si la obra-dice Toussaint-circuló antes de la muerte del General, que como hemos dicho ocurrió el 22 de noviembre del año mencionado [1896], y así debe creerse, pues lo asegura don Luis González Obregón... sin género de duda puede sostenerse que [la obra] no fue póstuma". ${ }^{2}$ Como el cuento "La limosna" se halla en la edición de 1896, puede ser que los editores de El Siglo XIX lo hayan copiado de allí. En este caso, tendríamos que fijar la fecha de publicación de Los Cuentos del General como anterior a marzo de 1896, fecha que nos parece bastante temprana. Existe la posibilidad, también, de que ambos cuentos hayan sido copiados de otros periódicos de la época, o de que el autor mismo los haya enviado desde Madrid.

Los anteriores apuntes nos dan una idea de la naturaleza de Los Cuentos del General. Es evidente que el autor reunió narraciones escritas en varias épocas. Por lo tanto, los temas presentan gran diversidad. Lo único que da unidad al volumen es la personalidad del autor: en todos ellos campea el humorismo y la ironía característicos de Riva Palacio. Ni aun en los cinco cuentos que por primera vez aparecen con el título "Cuentos del General" hay unidad; allí se incluyeron tanto cuentos históricos ("Los azotes", "La leyenda de un santo") como cuentos de ambiente madrileño ("La horma de su zapato").

Hay que advertir, sin embargo, que la diversidad de temas no resta mérito a la obra. Al contrario, esta misma variedad prohibe que la lectura sea monótona y aumenta, al mismo tiempo, el círculo de posibles lectores; en la colección hay cuentos para todos los gustos. Cierto tipo de lector, interesado en la época colonial, gozará leyendo "Las mulas de su Excelen-" cia”, narración al estilo de don Ricardo Palma. Estos cuentos

9 Op. cit., en n. 1, pág. XV. 
coloniales de Riva Palacio son superiores a sus novelas del mismo género. Ello se debe, tal vez, a que el autor da preferencia a la leyenda y olvida - lo que no puede o no trata de hacer en sus novelas-la realidad. Además, en los cuentos no cae en el error de querer imitar el lenguaje de los siglos XVI y XVII, característica de estilo que resta mérito a sus novelas históricas.

A pesar de la importancia del cuento colonial -precursor de las tradiciones nacionales de González Obregón-- no nos parece que sea el mejor de Riva Palacio. Los cuentos en que se supera son, en nuestra opinión, aquellos en los cuales relata una fábula o una anécdota cualquiera, no sacada de los antiguos cronicones, sino más bien oída a algún amigo o leída en algún diario o revista. Entre este tipo de cuento destacan los titulados "Un Stradivarius", "El buen ejemplo", "El divorcio" y "La horma de su zapato". Todos ellos - y otros de este tipo-giran en torno a una anécdota insignificante pero (característica del estilo de los mejores Cuentos del General), muy bien redondeada y contada en estilo lleno de gracia. Riva Palacio sabía sacarle el jugo a la anécdota más trivial; dichas anécdotas raras veces son originales. Ya hemos visto el caso de "El divorcio". El tema de "Un Stradivarius" ya lo había tratado Roa Bárcena en su excelente cuento "El cuadro de $\mathrm{Mu}$ rillo". Mas no son los temas lo que da valor a los cuentos del General; el mérito estriba en el estilo, ese estilo tan lleno de gracia y donaire. Sin duda Riva Palacio, el cuentista, es superior a Riva Palacio el novelista. Mientras que en sus novelas es descuidado en el estilo y difuso en los temas, en los cuentos se ciñe a la narración y la desarrolla en estilo cuidado y sobrio. Por estas razones, sus cuentos se seguirán leyendo, mientras que sus novelas siguen recogiendo polvo en los anaqueles de las bibliotecas.

Los Cuentos del General, repetimos con Manuel Toussaint, es libro de fácil lectura, de limpio criterio, realizado "con mano apta y pronta", libro que deja en el ánimo del lector una agradable sonrisa difundida en un gran bienestar.

LUIS LEAL, Emory University 
